\title{
Meltwater Infiltration into the Frozen Active Layer at an Alpine Permafrost Site
}

\author{
Martin Scherler, ${ }^{1 *}$ Christian Hauck, ${ }^{1}$ Martin Hoelzle,${ }^{1}$ Manfred Stähli ${ }^{2}$ and Ingo Völksch ${ }^{2}$ \\ 1 Department of Geosciences, University of Fribourg, Chemin de Musée 4, 1700 Fribourg, Switzerland \\ 2 Swiss Federal Research Institute WSL, Birmensdorf, Zurich, Switzerland
}

\begin{abstract}
A coupled heat and mass transfer model simulating mass and energy balance of the soil-snow-atmosphere boundary layer was applied to simulate ground temperatures, together with water and ice content evolution, in the active layer of an alpine permafrost site on Schilthorn, Swiss Alps. Abrupt shifts and subsequent fluctuations in ground temperature observed in alpine permafrost boreholes at the beginning of the zero curtain phase in summer were explained by snowmelt and meltwater infiltration. Simulated water contents were compared to values derived from inverted electrical resistivity measurements and yielded a further independent validation of the model results. The study shows that infiltration into frozen soil takes place as an oscillating process in the model. This process is constrained by initial ground temperatures, infiltrability and the availability of meltwater from the snow cover.
\end{abstract}

\begin{abstract}
KEY WORDS: infiltration; frozen ground; active layer; permafrost; non-conductive heat transfer; modelling; electrical resistivity tomography
\end{abstract}

\section{INTRODUCTION}

A number of studies of small-scale hydrothermal processes in latitudinal permafrost have shown that pore ice, fluid water and water vapour may coexist in frozen ground and lead to complex interactions during seasonal freeze-thaw cycles in the active layer (e.g. Kane and Stein, 1983; Outcalt et al., 1990; Romanovsky and Osterkamp, 2000). Unfrozen moisture can exist at sub-zero temperatures and advective water migration to the freezing front can redistribute water and ice, thus changing the thermal and hydrological properties of the soil (Kane and Stein, 1983; Trimble et al., 1958). Convective heat transfer via unfrozen pore water has been described by Outcalt et al. (1990) as the primary heat transfer process during the zero curtain phase, a time period where phase change in the active layer leads to isothermal conditions near the melting point.

Relatively little is known about infiltration into the active layer, even though it has been identified as contributing substantially to the energy exchange in permafrost (Kane et al., 2001). Infiltration typically occurs along preferential flow paths (Stähli et al., 1996; Boike et al., 1998; Ishikawa

* Correspondence to: Martin Scherler, Department of Geosciences, University of Fribourg, Switzerland. E-mail: martin.scherler@unifr.ch Contract/grant sponsors: Schilthornbahn AG; PERMOS. et al., 2006) during comparatively short time periods. Direct measurement of the phenomenon (e.g. using time-domain reflectometry, see Patterson and Smith, 1980) is difficult, especially in high mountain terrain, and tends to disturb the system itself. Therefore, in this study, we used electrical resistivity tomography (ERT) measurements combined with borehole temperature $\operatorname{logs}$ as alternative means to assess infiltration (French and Binley, 2004). This method can investigate spatial differences in the evolution of water and ice content over time spans of days to years (Hauck, 2002; Hilbich et al., 2008).

Numerical models have also proven useful to investigate energy and mass transfers among the atmosphere, snow cover and permafrost (Kane et al., 2001; Lunardini, 1998; Riseborough et al., 2008). In modelling studies, the importance of incorporating a seasonal snow cover as well as the effects of unfrozen water migration for time periods with freezing and thawing has been emphasised (Kane et al., 2001; Romanovsky and Osterkamp, 2000; Ling and Zhang, 2004).

Infiltration of meltwater from the snow cover may cause significant warming in frozen soils, which is revealed by a sudden temperature shift to the melting point in near-surface layers (Kane and Stein, 1983; Boike et al., 1998; Ishikawa et al., 2006). Similar temperature shifts were reported for the high-elevation permafrost station at Schilthorn, Swiss Alps (2970 m a.s.1.) (Hauck, 2001; Völksch, 2004) and have been 
registered repeatedly in borehole temperature logs over the past several years. In the summer of 2004, ground temperature fluctuations with magnitudes of $0.3^{\circ} \mathrm{C}-1.5^{\circ} \mathrm{C}$ were observed at depths of up to $7 \mathrm{~m}$ following the sudden shift to $0^{\circ} \mathrm{C}$ in the uppermost layers. Because a snow cover was present and the temperature measurements suggest that the heat spread very rapidly through much of the active layer, advective water flow is thought to have been the dominant mode of heat transfer.

We used two different approaches to investigate the hypothesised infiltration processes. First, we applied a numerical model for coupled mass and heat transfer (Jansson and Karlberg, 2001) to explore the influence of meltwater infiltration on a mountain permafrost site with fine-grained near-surface material. The model simulates infiltration into frozen ground and the purpose was to determine whether it could mimic the rapid rises in temperature observed during snowmelt. Second, the model was validated with the borehole temperature measurements from the field site. The ERT measurements provide an independent semi-quantitative additional validation of the functioning of the model.

\section{STUDY SITE}

The investigation site is the Schilthorn massif (Bernese Oberland, Switzerland), located in the north central part of the alpine arc. The Schilthorn has served as the subject of several mountain permafrost studies and is part of the ongoing Swiss monitoring programme PERMOS (Vonder Mühll et al., 2004) and the European PACE programme (Harris et al., 2001).

The lithology of the site is characterised by weathered surface material several metres in thickness (Hauck, 2001) underlain by strongly jointed micaceous shales. The thick layers of relatively fine-grained material on the surface are rarely found at alpine permafrost sites and result in comparatively high retention capacity and high hydraulic conductivity.

The slope faces north and has a gradient of about $30^{\circ}$. The active layer is about $5 \mathrm{~m}$ thick and the permafrost beneath extends to more than $100-\mathrm{m}$ depth with temperatures of $-0.7^{\circ} \mathrm{C}$. The ice content is generally low and mainly present as pore ice (Vonder Mühll et al., 2000).

Three boreholes are present, one $14 \mathrm{~m}$ deep and two $100 \mathrm{~m}$ deep, one of which is at an angle of $30^{\circ}$ to the mountain slope. Permafrost temperatures (Figure 1) have been collected by thermistor chains in the boreholes since 1998 (14 m, uninsulated, cables are inserted into the open hole which may have partially collapsed by now) and 2000 (100 m, insulated within a PVC pipe), while meteorological parameters have been measured at the site since 2001 (Stocker-Mittaz et al., 2002). All boreholes are protected from water infiltration with a cap. In 1999, a semi-automatic electrical resistivity array was permanently installed at the site. The array is situated on a small plateau perpendicular to the gradient (see Hilbich et al., 2008, Figure 2) and is used to monitor water and ice content distribution in the uppermost $10 \mathrm{~m}$ (Hauck, 2002; Hilbich et al., 2008).

Mean annual precipitation on the site is around $2700 \mathrm{~mm}$, of which about two-thirds falls as snow during the winter (Spreafico, 1992; Stocker-Mittaz et al., 2002). The snow cover reaches a maximum thicknesses of more than $5 \mathrm{~m}$ and can last from the beginning of October through to late July or even August (Imhof et al., 2000). Most infiltration and runoff occurs in the snowmelt period between June and August.

\section{MODEL}

The model used in this study is a one-dimensional soil water and heat transfer model (COUP model; Jansson and Karlberg, 2001). It accounts for the accumulation and melt of a seasonal snow cover, as well as for freezing and thawing of the soil. A detailed description of water infiltration into the frozen soil was implemented by Stähli et al. (1996), which makes the model particularly suitable for the present use.

The model is driven by air temperature, relative humidity, wind speed, global or net radiation, incoming long-wave radiation and precipitation. If air temperature is below a threshold value, precipitation falls as snow and builds up a snow cover that controls the upper boundary of the soil through its thermal insulation and its water storage for later release. The density of the snowpack is assumed to be uniform with depth, but variable in time as a function of settling and melting.

A complete energy balance is calculated for the snow or soil surface, as appropriate, resulting in a surface temperature that is the upper thermal boundary condition of the soil profile. The lower thermal boundary at a depth of $26 \mathrm{~m}$ is defined by a constant geothermal heat flux.

The soil is divided into an array of soil layers of progressively increasing thickness. Thermal and hydraulic parameters can be specified for the various layers. The soil layer properties vary in time according to their liquid water and ice content.

Heat and water fluxes are coupled through the general heat flow equation:

$$
\frac{\partial(C T)}{\partial t}-L_{f} \rho \frac{\partial \Theta_{i}}{\partial t}=\frac{\partial}{\partial z}\left(k \frac{\partial T}{\partial z}\right)-C_{w} T \frac{\partial q_{w}}{\partial z}-L_{v} \frac{\partial q_{v}}{\partial z}
$$

where $C\left(\mathrm{~J} \mathrm{~K}^{-1}\right)$ is the heat capacity, $T(\mathrm{~K})$ is the soil temperature, $L_{f}\left(\mathrm{~J} \mathrm{~kg}^{-1}\right)$ is the latent heat of freezing, $\rho$ $\left(\mathrm{kg} \mathrm{m}^{-3}\right)$ is the density, $\Theta_{i}$ is the volumetric ice content, $k$ $\left(\mathrm{W} \mathrm{m}^{-1} \mathrm{~K}^{-1}\right.$ ) is the thermal conductivity and $q_{w}$ and $q_{v}$ $\left(\mathrm{kg} \mathrm{m}^{-2} \mathrm{~s}^{-1}\right)$ are the water and vapour fluxes, respectively. The transition from frozen to unfrozen soil and vice versa occurs over a temperature range of 0 to $-5^{\circ} \mathrm{C}$, accounting for the freezing characteristics of the specific soil.

Depending on the soil water content prior to freezing and previous refreezing of infiltrating meltwater, frozen soil layers may completely or partially impede liquid water flow during spring snowmelt. However, subsequent thawing 
reduces the ice content of the frozen soil layers and therefore increases their hydraulic conductivity. The excess water at the surface or at a certain depth leads to a build-up of a surface water pool or a perched water table in the soil. Water flows laterally, depending on the hydraulic gradient that relates to the slope of the terrain. A detailed description of the model including all its equations and parameters is given in Jansson and Karlberg (2001) while its applications are detailed in a number of studies (e.g. Johnsson and Lundin, 1991; Stähli et al., 1996; Bayard et al., 2005).

Hourly meteorological data from Schilthorn were used to drive the model, except for precipitation which was derived from three nearby stations of the Federal Office of Meteorology and Climatology MeteoSwiss. Daily sums from Interlaken, Lauterbrunnen and Mürren were extrapolated to the elevation of Schilthorn with Equation (2) (Stocker-Mittaz et al., 2002):

$$
P_{2970}=P_{h 1}\left(\frac{h_{1}}{r_{e} P_{t o t}}-1\right)
$$

where $P_{2970}(\mathrm{~mm})$ stands for the amount of precipitation at $2970 \mathrm{~m}$ a.s.l., $P_{h l}(\mathrm{~mm})$ denotes the amount of precipitation at the height of the meteorological station, $P_{t o t}(\mathrm{~mm})$ is the estimated annual sum of precipitation at $2970 \mathrm{~m}$ a.s.l., $h_{l}$ is the altitude of the meteorological station (in $\mathrm{m}$ a.s.l.) and $r_{e}$ is a sitespecific coefficient determined for the Schilthorn to be 0.31 by Stocker-Mittaz et al. (2002). The daily precipitation values for Schilthorn obtained by this extrapolation were scaled proportionally to the hourly values from the station in Mürren, situated on a mountain-side $4 \mathrm{~km}$ east of the Schilthorn.

A 26-m deep soil profile was simulated with a total of 30 layers. Hydraulic soil properties were estimated from soil texture measurements of the surface material, which is 70 per cent sand, 18 per cent silt and 9 per cent clay, and has a porosity of 54 per cent. The model was calibrated experimentally using the observed temperature values of the 14-m deep borehole and the heat capacity and thermal conductivity of the solid soil material according to Carmichael (1988).

\section{TWO-DIMENSIONAL WATER CONTENT ESTIMATION}

In porous materials at temperatures below $0^{\circ} \mathrm{C}$, water may be present as a solid, fluid or vapour. The fluid phase can persist even at temperatures far below the freezing point (Bouyoucos and McCool, 1916; Anderson et al., 1973). Assuming that electrical current in soils is primarily conducted through ionic migration in the pore fluid, most of the electrical resistivity change that can be determined by means of geoelectrical resistivity measurements will be due to changes in water content (Loke, 2000; Hauck, 2002). Thus, low resistivity readings indicate high water content or high ionic strength, while high readings indicate low water content or low ionic strength. Assuming that pore space distribution and ionic strength of a measured soil profile do not change significantly between two measurements, resistivity differences over time can yield semi-quantitative information about changes in water or ice content (Hilbich et al., 2008).

Two-dimensional ERT was used to give a rapid, qualitative overview of the evolution of soil moisture over a relatively large area. Rings et al. (2008) showed that this method is also suitable for locating and identifying the temporal occurrence of infiltration events in the upper subsurface. Furthermore, inverted resistivity values were used to determine the water content of the subsurface during the infiltration period at a temporal resolution of days to weeks.

All measurements were conducted between 0900 and 1100 local time using an array of 30 electrodes with 2-m spacing (Hauck, 2002). A Wenner electrode configuration was chosen because of its optimal characteristics regarding depth of investigation, signal-to-noise ratio and the time needed to collect the dataset consisting of 135 datum points. The spatial resolution obtained after inversion with the commercial software Res2DINV (Loke, 2000) is $1 \mathrm{~m}$ horizontally, with a vertical resolution of $0.5 \mathrm{~m}$ at the top and decreasing with depth. All datasets were inverted individually using standard inversion parameters. The depth of investigation reached approximately $10 \mathrm{~m}$, encompassing the active layer and the uppermost part of the permafrost.

Archie's law (Archie, 1942) was used to derive the water content from the measured bulk soil electrical resistivity:

$$
\rho_{s}=a \rho_{w} \Phi^{-m} S^{-n}
$$

where $\rho_{s}$ is the electrical resistivity of the soil as determined by ERT measurements $(\Omega \mathrm{m}), \rho_{w}$ is the resistivity of the pore fluid $(7.4 \Omega \mathrm{m}), \Phi$ is the porosity $(0.54), S$ is the saturation of the soil, and $\{a, m, n\}=\{1,1.4,2\}$ are empirical parameters calibrated experimentally on the basis of soil analysis and

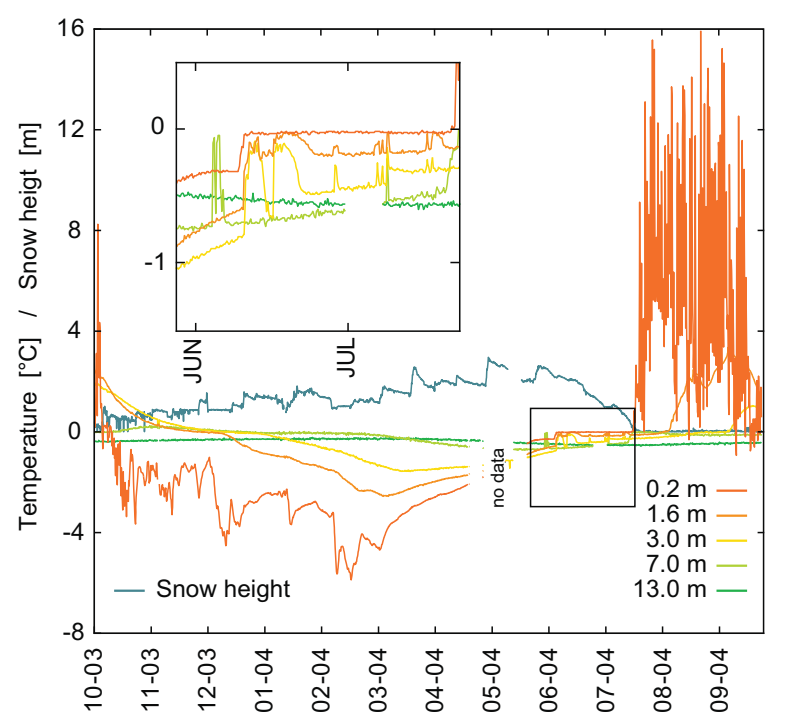

Figure 1 Observed borehole temperatures and measured snow depth (m) for 2003-04. Inset shows the borehole temperatures in June and July 2004. 
ERT measurements from October 2004 and using ranges found in the literature (Keller and Frischknecht, 1966). The resistivity of the pore fluid was determined from electrical conductivity (EC) measurements of field-moist soil samples. Demineralised water was added to the soil (to twice the initial volume of the sample) and stirred for $1 \mathrm{~h}$ (Black, 1965), the solution was filtered and diluted, and the EC was measured with a conductivity meter. The value for the original concentration was then extrapolated by fitting an exponential relationship to the measurements.

\section{RESULTS}

\section{Field Observations}

Measured temperatures from the 14-m deep borehole illustrate the thermal regime of the active layer and the near-surface
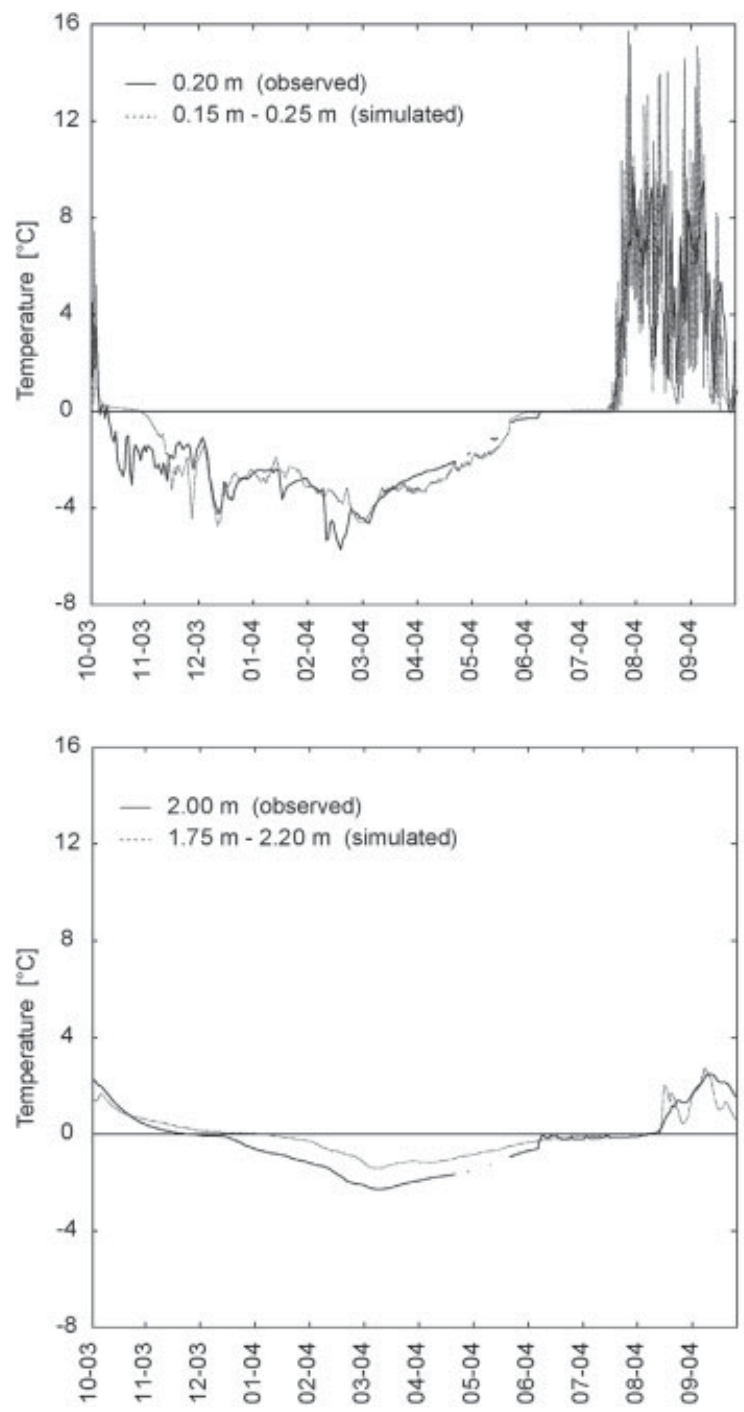

permafrost on Schilthorn (Figure 1). In the observation period from October 2003 to October 2004, the active layer extended to a depth of $7 \mathrm{~m}$ to $9 \mathrm{~m}$ below the surface. This is much deeper than in preceding years, reflecting the exceptionally warm summer of 2003 in the European Alps (see Schär et al., 2004; Hilbich et al., 2008).

In autumn 2003, with mean daily air temperatures below $0^{\circ} \mathrm{C}$ and a thin snow cover in October, ground temperatures near the surface rapidly fell below the freezing point. The formation of ice at the freezing front then progressed from the surface into deeper layers. After a relatively short zero curtain period, the ground cooled continuously with progressive lags at greater depths and damped amplitudes. After warming from mid-February to June, initially driven by conductive heat transfer from the bottom of the active layer, temperatures suddenly increased to nearly $0^{\circ} \mathrm{C}$ (see inset in Figure 1). Following this abrupt shift, nearsurface layers remained isothermal, indicating zero curtain
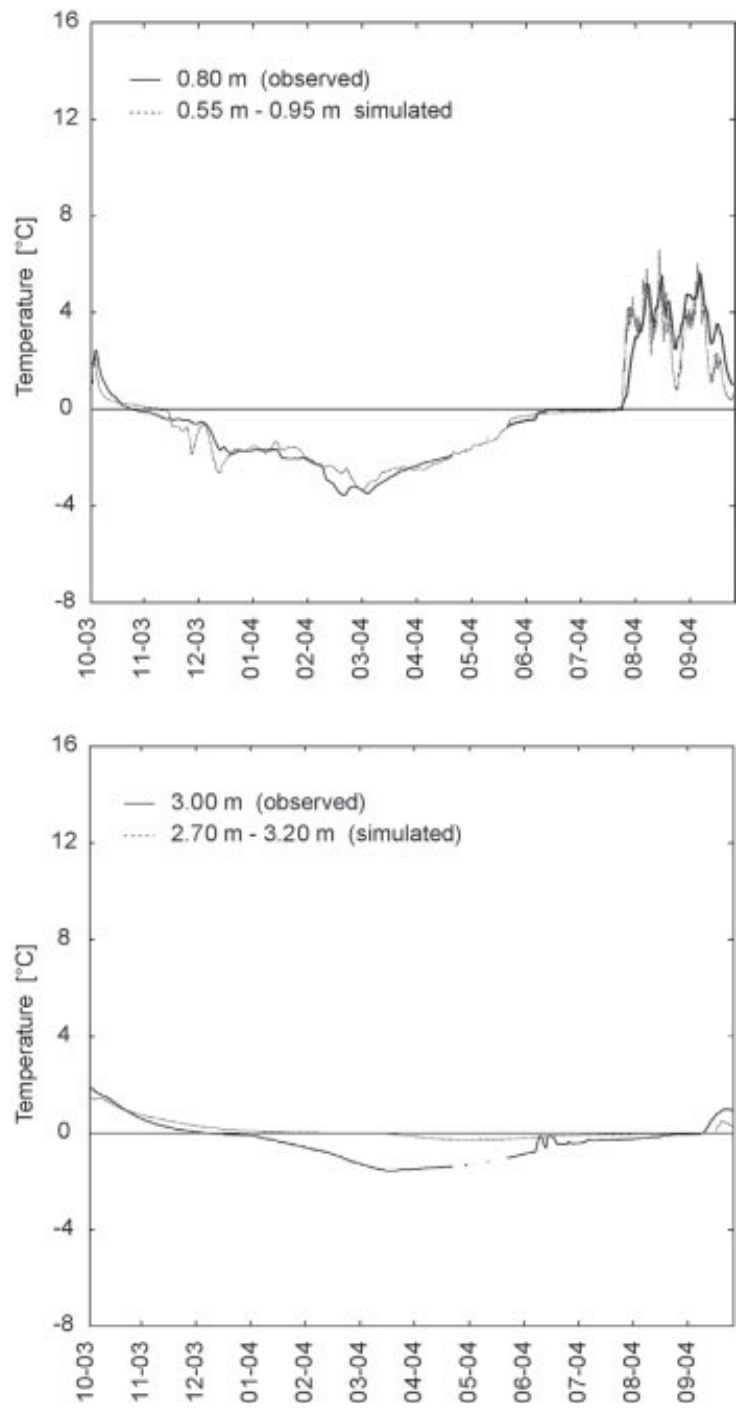

Figure 2 Borehole temperature data compared to simulated temperatures for four depths within the active layer. 
conditions. Deeper layers cooled by about $0.1{ }^{\circ} \mathrm{C}$, with the maximum amplitude being attained at a depth of $3 \mathrm{~m}$ between 10 and 15 June (Figure 1). A similar temperature fluctuation recurred after a few days. The temperature peak at 7-m depth suggests that meltwater had infiltrated upslope of the borehole and flowed laterally.

\section{Simulation}

Measured and simulated temperatures were compared for 2003-04 for depths ranging from $0.2 \mathrm{~m}$ to $3 \mathrm{~m}$ below the surface (Figure 2). The best correlations were present for soil layers in the upper $2 \mathrm{~m}$.

Figure 3 shows the simulated water and ice contents in the surface layer $(0-5 \mathrm{~cm})$. At the onset of freezing the water content was around 4 per cent, but the ice volume formed during freezing was about five times as great. Thus the pores became saturated with ice and unfrozen water, significantly lowering hydraulic conductivity as has been observed previously for seasonally frozen ground (Kane, 1980; Trimble et al., 1958). The concentration of moisture in the top layer is explained by upward migration of unfrozen water during winter towards the advancing freezing front. During ablation of the snow cover, ice and water contents fluctuated in the surface layer for 2 months. The changes in the ice content of the top layer (persisting until late July) indicate freezing and thawing cycles under snow-covered conditions, and thus a highly variable infiltration capacity.

Modelled results for infiltration, refreezing of water in the top soil layer, the formation of a surface water pool and ground temperature for the 2.2-2.7-m depth are shown in Figure 4 for June 2004. The results from the model show temperature shifts (Figure 4a) occurring simultaneously with infiltration. The process is interpreted as follows: infiltration occurs until a critical amount of water has

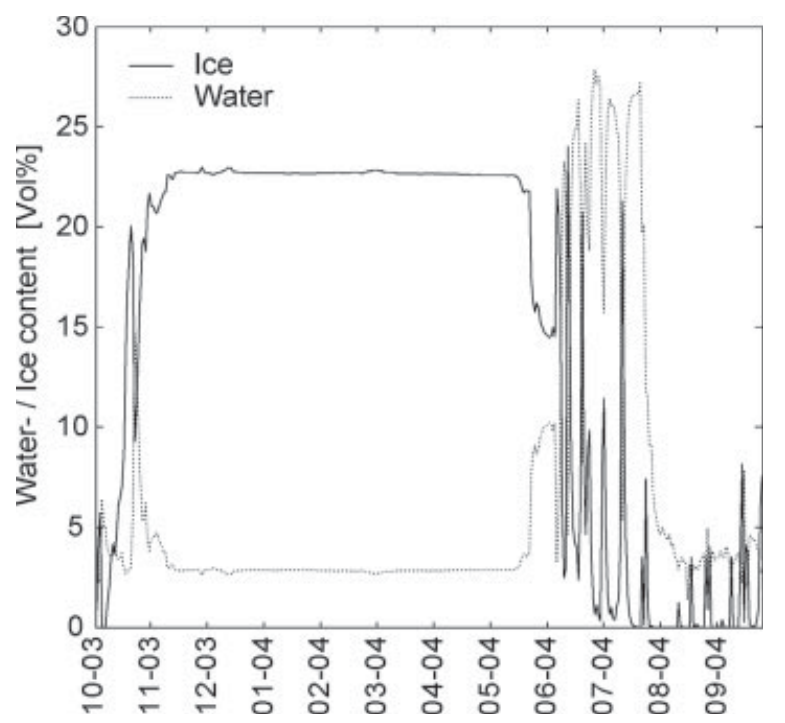

Figure 3 Simulated water and ice contents of the surface layer $(0-5 \mathrm{~cm})$ for 2003-04. refrozen in the top soil layer, so that the pore space is filled with ice, reducing water inputs to almost zero (Figure 4b) and shutting off advective heat flow into the soil. Meltwater then fills the surface pool (Figure 4d). The temperature of the soil layer falls due to conductive heat flow to lower soil layers. As water flow from the snow cover continues and the surface pool is filled to a critical pressure head, ice in the top soil layer melts and water is released into the ground (Figure 4c). This process is repeated until the temperatures in the active layer have risen to a point where percolating water will no longer refreeze in the surface layer.

\section{Water Contents}

Two surveys of water contents conducted by ERT within $2 \mathrm{~h}$ indicate only very small differences on the left side of the profile, which implies significant freezing processes only in proximity of the 14-m borehole (Figure 5). In the following 14-day period, a change in water content is apparent on the left side of the profile from slightly below 0 per cent to +4 per cent in the upper part of the active layer. Such increases in moisture in a relatively small area suggest that the cause is preferential infiltration rather than in-situ melt of ice. During the 3 months from the end of June to the beginning of October, the observed decrease in water content throughout large parts of the profile may be explained by evaporation at the surface, and at greater depths, by the lateral outflow of meltwater.

Figure 6 shows water content values in the upper part of the active layer obtained from the simulation compared to values derived from the ERT measurements. Even though the simulation results cannot be directly compared to the ERT values, as no data are available during the critical thawing phase, a general agreement is evident. The ERTderived values for October 2003 were higher than the model results for all four depths, but the relative decrease until the beginning of the thawing period is about the same magnitude in both. The same is true for the increase during the snowmelt period from May to July when most of the measurements were conducted. Simulated values indicate the increasing water content caused by melting ice or infiltration, and thus increasing water contents coincide with periods when observed values show that the active layer was starting to thaw. The total increase in water content within the following zero curtain phase is smaller in the model results than in the measurements at depths below $25 \mathrm{~cm}$, but shows similar gradients at all four depths.

\section{DISCUSSION}

When comparing the ERT-derived and simulated water content values, various sources of uncertainty have to be considered. First, the model could not be initialised to thermodynamic equilibrium due to unknown proportions of unfrozen water and heat contents of the soil layers. Second, there is insufficient drainage with increasing depth, or no lateral outflow from unsaturated layers in the model soil 


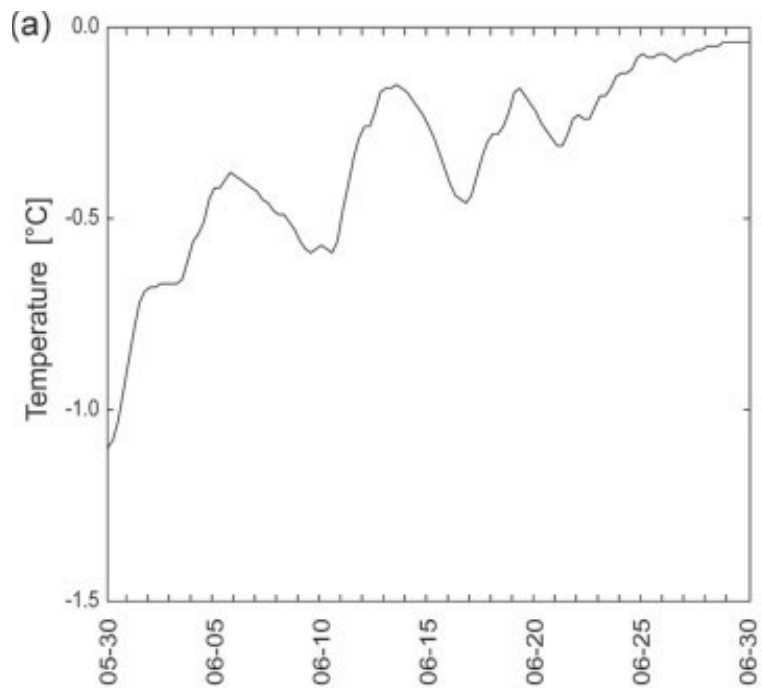

(c)

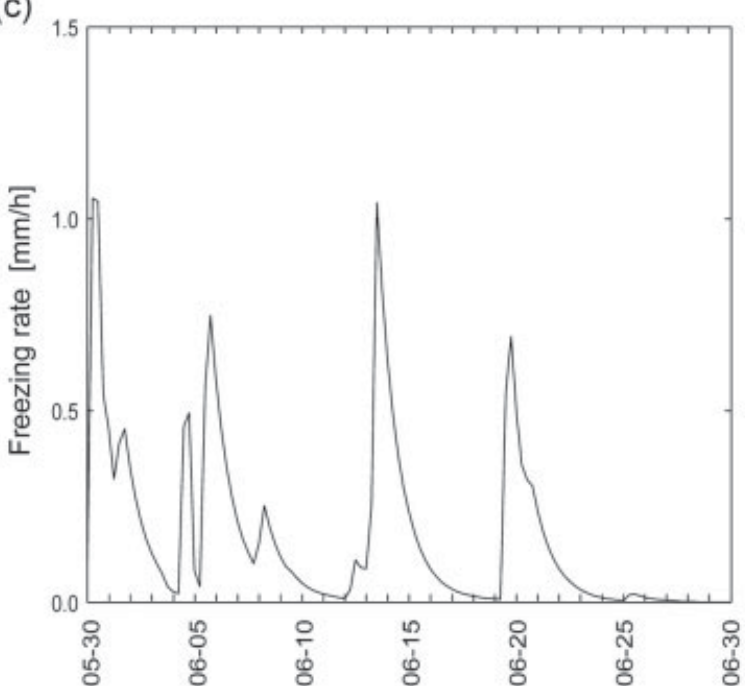

(b)

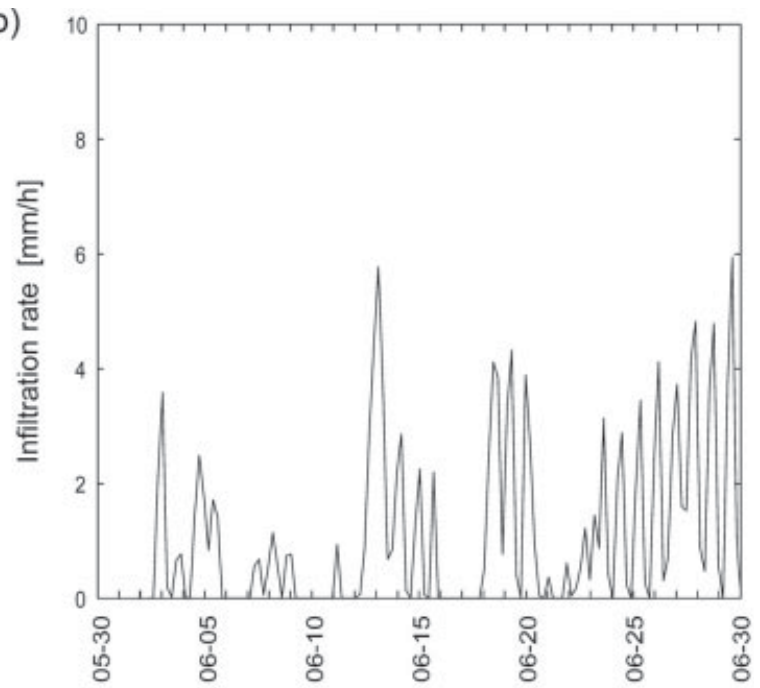

(d)

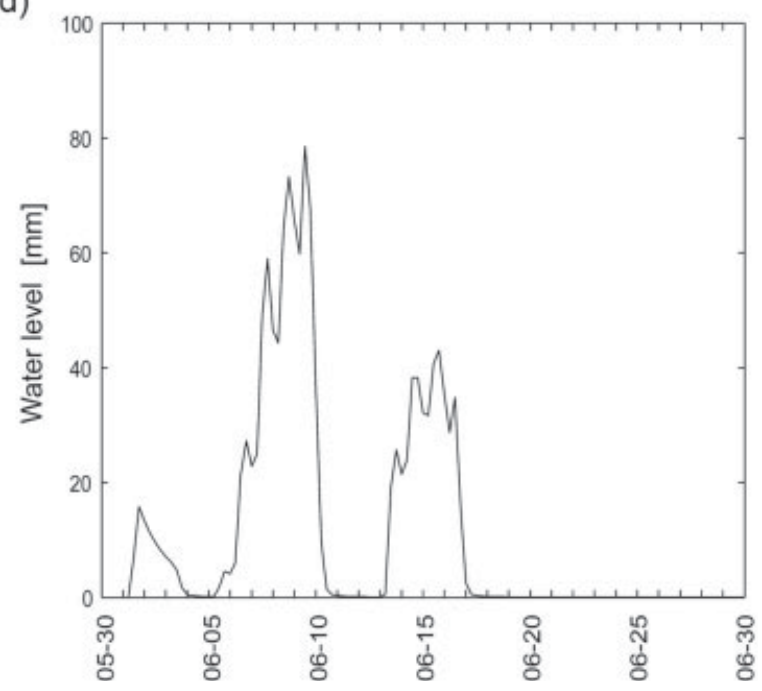

Figure 4 Simulated infiltration events for June 2004 as shown by (a) temperature of the 2.2-2.7-m deep layer, (b) surface infiltration rate, (c) refreezing rate in the surface layer and (d) formation of the surface pool.

columns, which led to overestimated water contents at the end of the simulation period. Third, temperatures were measured in a borehole which might have different hydraulic properties from those of its surroundings. Finally, ERT measurements for frozen ground can provide results that are ambiguous between drying-freezing and percolation-thawing. Furthermore, artefacts may occur during the inversion process. These points are discussed in greater detail below

\section{Model}

Model simulations showed that subsurface temperature fluctuations prior to complete thawing of the active layer in early summer can be caused by infiltrating meltwater from the snow cover. The processes described in the results section depend on very small changes in the parameters controlling the hydraulic properties of the soil, in particular on the infiltration properties. The latter are strongly constrained by pore space and temperature. Because pore space is influenced by unfrozen water and ice content, model parameters specifying the refreezing of infiltrating water are also of critical significance (Stähli et al., 1999).

The processes causing the temperature shifts in the model cannot be directly compared to the situation in the field, because ground temperature measurements from Schilthorn are obtained from thermistors in an uninsulated borehole (initially filled with air), whereas simulated temperatures correspond to the heat content of a soil compartment. The borehole itself may represent a large macropore which would allow for faster and deeper propagation of infiltrating water than may occur in the surrounding fine-grained soil. Nevertheless, water which flows into the borehole must first pass through the fine-grained surface material before it can 


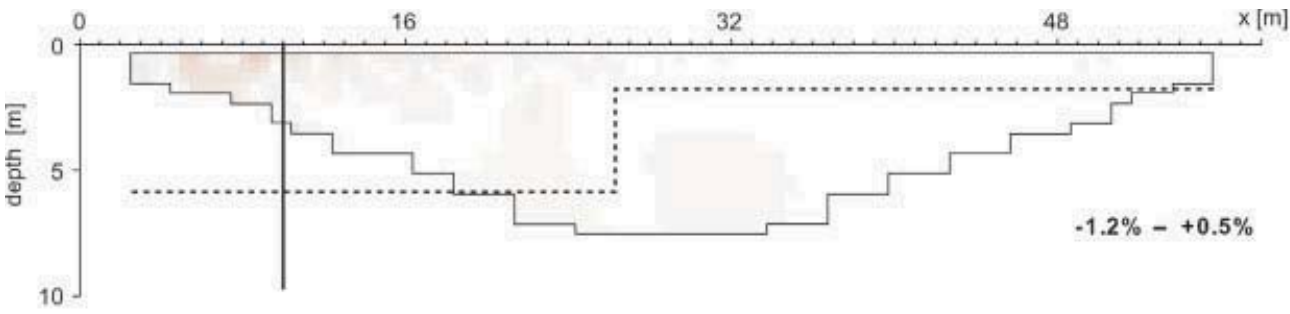

2 hours

15 Jun $04 / 15$ Jun 04

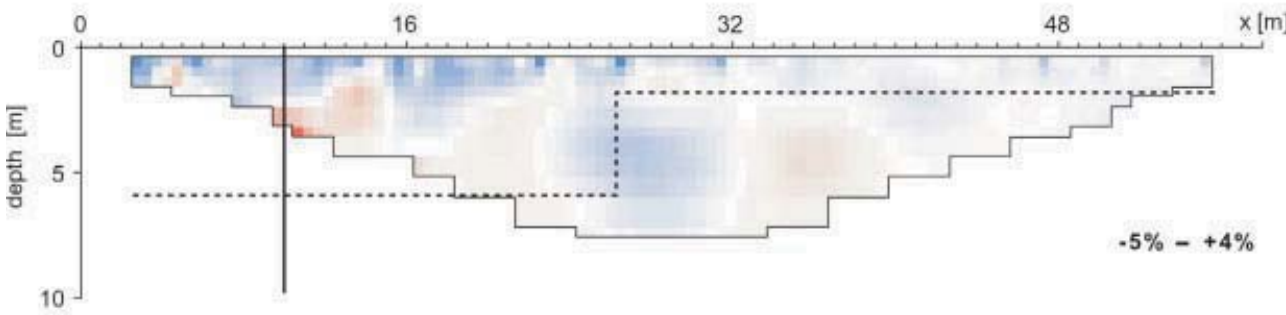

14 days

29 Jun $04 / 15$ Jun 04

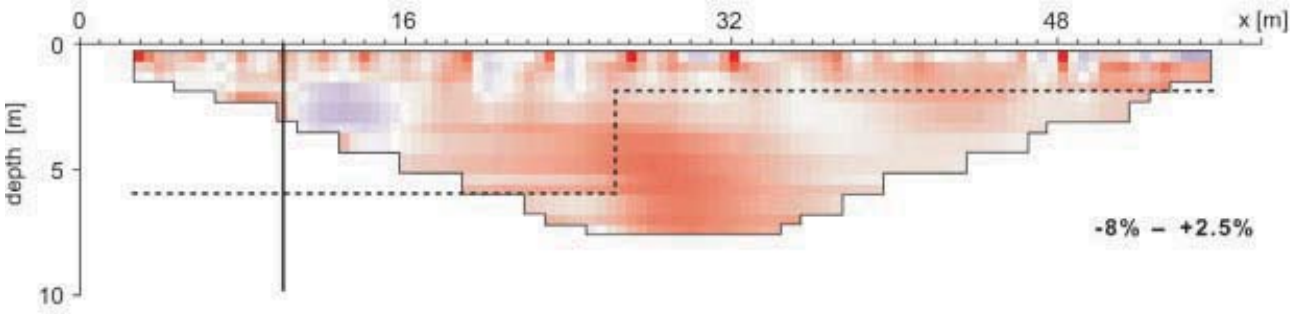

96 days

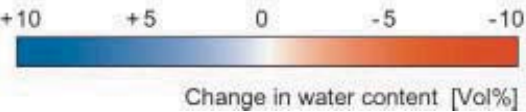

Figure 5 Water content changes in the active layer and near-surface permafrost evaluated using electrical resistivity tomography and Equation (3) during 2004 for successive periods of $2 \mathrm{~h}$ (15 June), 14 days (15-29 June) and 96 days (29 June-3 October). The vertical black line indicates the location of the 14-m borehole, the dashed line represents the bedrock boundary (determined by a refraction seismic survey, Hauck, 2001). Minimum and maximum differences are given in the lower right corner of each section. The geometry and blocky structure of the sections originate from the inversion process.

enter the hole laterally. Thus, even if lateral flow does enter the borehole, the infiltration process may still be similar to the one simulated in the model.

Problems in the simulation were encountered in the initialisation (temperatures and water contents). Initial model temperatures, slightly below $0^{\circ} \mathrm{C}$ at the interface between the active layer and the permafrost, were generally overestimated because the initial ice content could not be specified. Energy deficits (i.e. negative initial temperatures) were transferred into ice and unfrozen water content until a thermodynamic equilibrium was reached. As a consequence a rise in temperature occurred. A second problem related to the model's one-dimensionality because this precluded any account being taken of lateral inflow from soil compartments upslope.

\section{ERT}

Changes during the chronological series of resistivity images of frozen ground can be caused by water outflow and inflow (i.e. infiltration, water flow, evaporation or condensation), or by the freezing and thawing of porewater. A high water content in the soil profile may increase the EC of the soil due to enhanced ionic mobility in the pore fluid, thus yielding a lower resistivity value than it would for the same profile under dry conditions. Temperature changes, which are quite large in some parts of the profile, may also influence electrical resistivity, as heat increases the EC of both the fluid and solid phases in the soil (Keller and Frischknecht, 1966). Temperature dependence of electrical resistivity in soils is linear above $0^{\circ} \mathrm{C}$ with a decrease in resistivity of 2.5 per cent/ ${ }^{\circ} \mathrm{C}$ (Keller and Frischknecht, 1966), but it is exponential below $0^{\circ} \mathrm{C}$ largely due to variable ice content (and pore space) and thus variable ionic mobility (Hauck, 2001). The EC is usually increased by the ionisation of clay minerals and surface conductance, thus this calculation will overestimate conductivity through ionic migration by the amount conducted by these mechanisms. Consequently, water contents calculated through Archie's law tend to be too high. Because porosity was also chosen to be constant through time and throughout the whole profile, the method tends to underestimate water contents in the case of high ice contents or in areas with lower porosities (e.g. underlying bedrock). For the comparatively small temperature ranges that are encountered during thawing, however, any large resistivity 

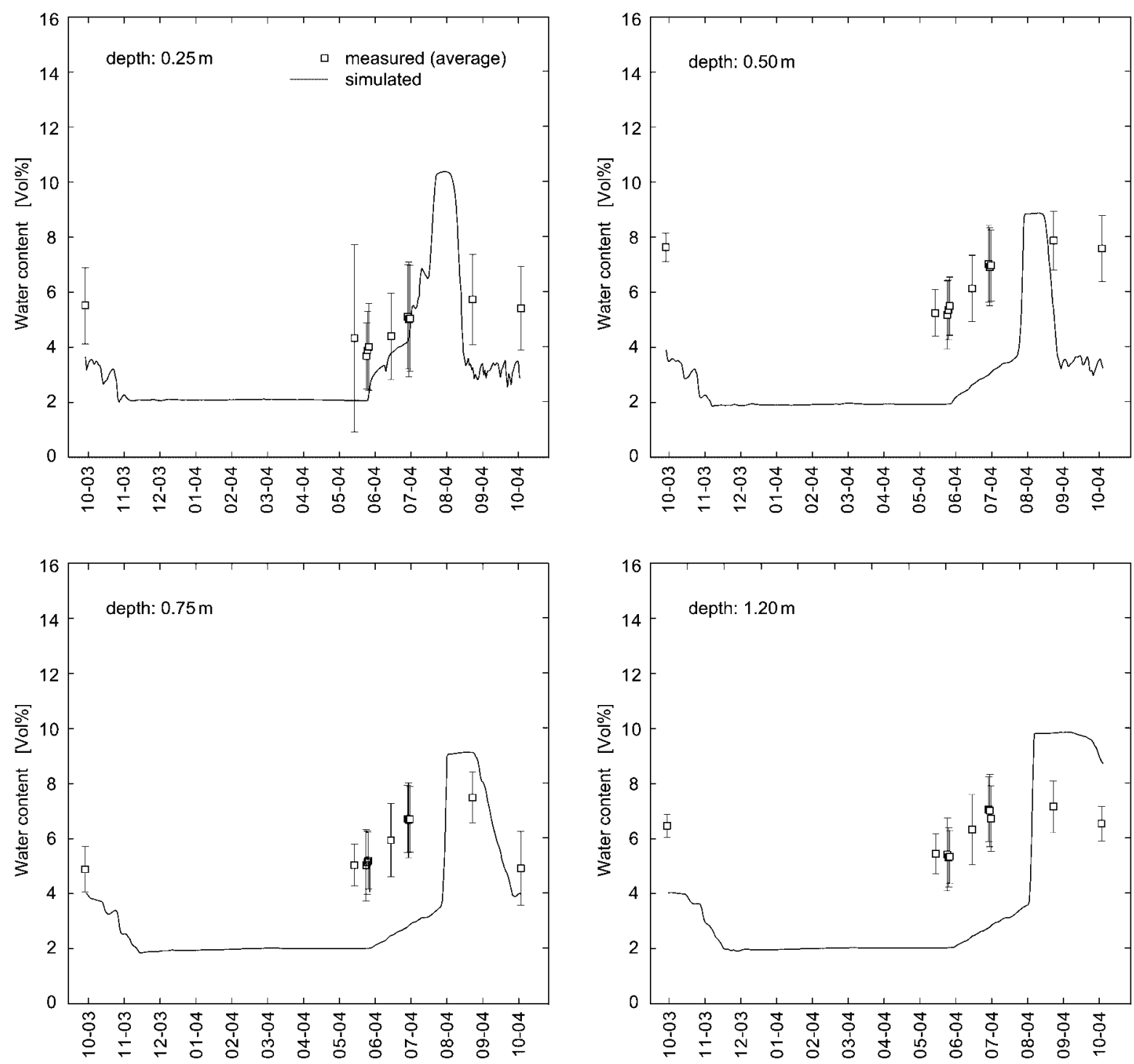

Figure 6 Water contents at four different depths derived from electrical resistivity tomography (ERT) measurements compared to simulated values for 200304. As the soil samples used for the calibration of Archie's law were taken from a spot about $10 \mathrm{~m}$ from the electrode array, water content values derived from observed ERT values have been averaged over the whole 60 -m profile. The bars indicate \pm 1 standard deviation. The simulated values represent one data point per layer.

contrasts obtained from near the surface may be reliably identified as changes in water content.

Undesirable artefacts may occur in the tomograms during resistivity inversion when large resistivity contrasts are present. However, these inaccuracies develop predominantly at greater depths, where the sensitivity of the method is diminished, below the area of largest resistivity increase or decrease (Rings et al., 2008; Marescot et al., 2003; Hilbich et al., 2008).

\section{Synopsis}

In spite of the limitations discussed above, the results suggest good qualitative agreement between measurements and model results. For example, on 15 June, the ERT-derived water content change indicated a slight decrease in water contents near the location of the 14-m borehole (Figure 5), which corresponds to refreezing processes seen in the simulations for that time (Figure $4 \mathrm{c}$ ). The fact that the magnitude of the decrease in water content during freezing and the increase during thawing (until the end of zero curtain phase) is similar for both methods (Figure 6) is also regarded as significant. Large deviations between measurements and model results may have occurred because the model overestimates the amount of infiltration during snowmelt due to insufficient surface and lateral runoff. In addition, the limited temporal resolution of the ERT data prohibited a thorough comparison of the processes on smaller time 
scales. Even though a rigorous proof of these processes cannot be undertaken without further direct evidence, both methods clearly indicate meltwater infiltration under snowcovered conditions into the still-frozen active layer.

\section{CONCLUSIONS}

The simulation results of this study provide additional indications that during the freezing period in dry soils water movement towards the freezing front may result in a low hydraulic conductivity layer near the surface that is impermeable to infiltration at the onset of snowmelt. However, the results also suggest that, despite this initial inhibition, infiltration can take place if the surface water level reaches a critical pressure head. Thus, infiltration into the frozen active layer at temperatures below $0^{\circ} \mathrm{C}$ occurs as an oscillating process, which is constrained by initial temperatures, infiltrability (which is modified by changing ice contents and temperature) and the availability of meltwater from the snow cover.

An infiltration cycle in the model begins when a critical amount of meltwater has accumulated, leading to melting processes in the surface layer, which in turn increase hydraulic conductivity sufficiently that infiltrating meltwater percolates and reaches greater depths. When the water pool at the ground surface is emptied, water refreezes on the surface and the top layer is again sealed by ice, which ends the cycle. As a result, heat is introduced into the ground by percolation, total water content increases and the meltwater eventually refreezes. The temperature fluctuations induced by these infiltration events end when soil temperatures are too high to permit refreezing of percolating water. This simulated process is in good agreement with changes in borehole temperatures and additional independent ERT-derived water content estimates at the permafrost site on Schilthorn.

\section{ACKNOWLEDGEMENTS}

The authors would like to thank the Schilthornbahn AG and the PERMOS network for logistical and financial support. We sincerely thank A. Lewkowicz for his thorough editing and two anonymous reviewers for their helpful comments.

\section{REFERENCES}

Anderson DM, Tice AR, McKim HL. 1973. The unfrozen water and the apparent specific heat capacity of frozen soils. In Permafrost: North American Contributions to the Second International Conference, Yakutsk, Siberia, USSR. National Academy of Sciences, Washington, DC. 20418, 289-295.

Archie GE. 1942. The electrical resistivity $\log$ as an aid in determining some reservoir characteristics. In Transactions of the American Institute of Mining, Metallurgical and Petroleum Engineers, Incorporated, American Institute of Mining and Metallurgical Engineers, New York, NY. Vol. 146, 54-62.
Bayard D, Stähli M, Parriaux A, Flühler H. 2005. The influence of seasonally frozen soil on the snowmelt runoff at two Alpine sites in southern Switzerland. Journal of Hydrology 309: 66-84. DOI: 10.1016/j.jhydrol.2004.11.012.

Black CA. 1965. Methods of Soil Analysis. Part 2: Chemical and Microbiological Properties, Number 9. American Society of Agronomy: Madison.

Boike J, Roth K, Overduin PP. 1998. Thermal and hydrologic dynamics of the active layer at a continuous permafrost site (Taymyr Peninsula, Siberia). Water Resources Research 34(3): 355-363.

Bouyoucos GJ, McCool MM. 1916. Further studies on the freezing point lowering of the soils. Technical Report 31, Michigan Agricultural College Experimentation Station.

Carmichael RS (ed.). 1988. Practical Handbook of Physical Properties of Rocks and Minerals. CRC Press, Boca Raton, FL.

French H, Binley A. 2004. Snowmelt infiltration: monitoring temporal and spatial variability using time-lapse geophysics. Journal of Hydrology 297(1): 174-186. DOI: 10.1016/j.jhydrol.2004.04.005.

Harris C, Haeberli W, Vonder Mühll D, King L. 2001. Permafrost monitoring in the high mountains of Europe: The PACE Project in its global context. Permafrost and Periglacial Processes 12(1): 3-12. DOI: 10.1002/ppp.377.

Hauck C. 2001. Geophysical methods for detecting permafrost in high mountains. Mitt. Versuchsanst. Wasserbau, Hydrologie und Glaziologie vol. 171, ETH Zürich

Hauck C. 2002. Frozen ground monitoring using DC resistivity tomography. Geophysical Reseach Letters 29(21): 2016. DOI: $10.1029 / 2002$ GL014995.

Hilbich C, Hauck C, Hoelzle M, Scherler M, Völksch I, Vonder Mühll D, Mäusbacher R. 2008. Monitoring of mountain permafrost evolution using electrical resistivity tomography: A 7-years study of seasonal, annual and long-term variations at Schilthorn, Swiss Alps. Journal of Geophysical Research 113: F01S90. DOI: 10.1029/2007JF000799.

Imhof M, Pierrehumbert G, Haeberli W, Kienholz H. 2000. Permafrost investigation in the Schilthorn massif, Bernese Alps, Switzerland. Permafrost and Periglacial Processes 11(3): 189-206. DOI: 10.1002/1099-1530(200007/ 09)11:3<189::AID.-PPP348>3.0.CO;2-N

Ishikawa M, Zhang Y, Kadota T, Ohata T. 2006. Hydrothermal regimes of the dry active layer. Water Resources Research 42 : W04401. DOI: 10.1029/2005WR004200.

Jansson P-E, Karlberg L. 2001. Coupled heat and mass transfer model for soil-plant-atmosphere systems. Royal Institute of Technology, Dept of Civil and Environmental Engineering, Stockholm.

Johnsson H, Lundin L-C. 1991. Surface runoff and soil water percolation as affected by snow and soil frost. Journal of Hydrology 122(3): 141-159. DOI: 10.1016/00221694(91)90177-J.

Kane D. 1980. Snowmelt infiltration into seasonally frozen soils. Cold Regions Science and Technology 3: 153-161.

Kane DL, Stein J. 1983. Water movement into seasonally frozen soils. Water Resources Research 19(6): 1547-1557.

Kane DL, Hinkel KM, Goering DJ, Hinzman LD, Outcalt SI. 2001. Non-conductive heat transfer associated with frozen soils. Global and Planetariy Change 29: 275-292. DOI: 10.1016/S0921-8181(01)00095-9.

Keller GV, Frischknecht FC. 1966. International Series of Monographs on Electromagnetic Waves, Volume 10. Pergamon Press: Oxford. 
Ling F, Zhang T. 2004. A numerical model for surface energy balance and thermal regime of the active layer and permafrost containing unfrozen water. Cold Regions Science and Technology 38(1): 1-15. DOI: 10.1016/S0165-232X(03)00057-0.

Loke MH. 2000. Electrical imaging surveys for environmental and engineering studies, a practical guide to 2-D and 3-D surveys. http://www.terrajp.co.jp/lokenote.pdf. accessed 31 May 2010.

Lunardini VJ. 1998. Effect of convective heat transfer on thawing of frozen soil. In Proceedings, 7th International Conference on Permafrost, Lewkowicz AG, Allard M (eds). Université, Sainte-Foy: Quebec; Yellowknife, Canada. Nordicana: 57, 689-695.

Marescot L, Loke MH, Chapellier D, Delaloye R, Lambiel C, Reynard E. 2003. Assessing reliability of 2D resistivity imaging in permafrost and rock glacier studies using the depth of investigation index method. Near Surface Geophysics 1(2): 57-67. DOI: 10.3997/1873-0604. 2002007.

Outcalt S, Nelson FE, Hinkel KM. 1990. The zero-curtain effect: Heat and mass transfer across an isothermal region in freezing soil. Water Resources Research 26(7): 1509-1516.

Patterson DE, Smith MW. 1980. The use of time domain reflectometry for the measurement of unfrozen water content in frozen soils. Cold Regions Science and Technology 3(2-3): 205-210.

Rings J, Scheuermann A, Preko K, Hauck C. 2008. Soil water content monitoring on a dike model using electrical resistivity tomography. Near Surface Geophysics 6: 123-132. DOI: 10.3997/ 1873-0604. 2007038.

Riseborough D, Shiklomanov N, Etzelmüller B, Gruber S, Marchenko S. 2008. Recent advances in permafrost modelling. Permafrost and Periglacial Processes 19(2): 137-156. DOI: $10.1002 / p p p .615$.

Romanovsky V, Osterkamp T. 2000. Effects of unfrozen water on heat and mass transport processes in the active layer and permafrost. Permafrost and Periglacial Processes 11: 219_
239. DOI: 10.1002/1099-1530(200007/09)11:3<219::AID.PPP352>3.0.CO;2-7

Schär C, Vidale PL, Lüthi D, Frei C, Häberli C, Liniger MA, Appenzeller C. 2004. The role of increasing temperature variability for European summer heat waves. Nature 427(6972): 332-336. DOI: 10.1038/nature02300.

Spreafico M. 1992. Hydrologischer Atlas der Schweiz. EDMZ: Landeshydrologie und -geologie: Bern.

Stähli M, Jansson P-E, Lundin L-C. 1996. Preferential water flow in a frozen soil - a two-domain model approach. Hydrological Processes 10: 1305-1316. DOI: 10.1002/ (SICI)1099-1085(199610)10:10<1305::AID.HYP462>3.0.CO;2-F

Stähli M, Jansson P-E, Lundin L-C. 1999. Soil moisture redistribution and infiltration in frozen sandy soils. Water Resources Research 35(1): 95-103.

Stocker-Mittaz C, Hoelzle M, Haeberli W. 2002. Modelling alpine permafrost distribution based on energy-balance data: a first step. Permafrost and Periglacial Processes 13: 271282. DOI: $10.1002 / \mathrm{ppp} .426$.

Trimble GR, Richard JR, Sartz S, Pierce RS. 1958. How type of soil frost affects infiltration. Journal of Soil and Water Conservation 13(2): 81-82.

Völksch I. 2004. Untersuchung und Modellierung kleinräumiger Unterschiede im Verhalten von Gebirgspermafrost Master's thesis, Swiss Federal Institute of Technology, Zurich.

Vonder Mühll D, Hauck C, Lehmann F. 2000. Verifcation of geophysical models in Alpine permafrost using borehole information. Annals of Glaciology 31: 300-306. DOI: 10.3189/172756400781820057.

Vonder Mühll D, Noetzli J, Makowski K, Delaloye R. 2004. Permafrost in Switzerland 2000/2001-2001/2002, glaciological report (permafrost) no. 2/3. Glaciological Commission of the Swiss Academy of Sciences and Department of Geography, University of Zurich, 86pp. 